\title{
Major Concerns? A Longitudinal Analysis of Student- Athletes' Academic Majors in Comparative Perspective
}

\author{
James P. Sanders and Kasee Hildenbrand \\ Washington State University
}

\begin{abstract}
This paper investigates the over-representation of student-athletes in academic majors, a pattern known as clustering. Three issues are examined. The first is whether clustering occurs at college entrance or later. The second is whether some athletes are at extra risk of clustering. The third is whether clustering contributes to future income inequalities. Analyses of a major university's student records revealed that athletes clustered at the start of college but the tendency to do so was moderated by race, sex, and type of sport played. Clustering also intensified greatly over time, particularly for African American athletes. By the eighth semester, $64 \%$ of African American athletes were social science majors. In the short-term, clustering lowered athletes' projected incomes, but long-term income projections based on academic major slightly favored groups of athletes who clustered within the social sciences.
\end{abstract}

The National Collegiate Athletic Association (NCAA) adjusted student athlete academic eligibility rules in 2003 . The new rules have generated concern over athlete clustering (e.g., Fountain \& Findlay, 2009; Leiber Steeg, Upton, Bohn, \& Berkowitz, 2008; Sack, 2009) a pattern in which athletes are disproportionately represented in academic majors (most often in the social sciences). Although evidence suggests that athlete clustering is widespread (Upton \& Novak, 2008), only a few studies have examined the issue in detail. Thus, important questions remain unanswered. First, why do athletes cluster? Is it because athletes are predisposed to cluster upon matriculating or because participation in college athletics narrows their academic options? An answer to this question is needed to advance theoretical understanding of the mechanisms that drive clustering. Second, (how) do demographic and social factors interact with student-athlete status? For example, is clustering a greater problem among men or African American athletes than among women or White athletes? Does the sport matter? Answers to these questions will highlight which groups of athletes are at greatest risk of clustering. Lastly, does clustering promote future income inequalities or is the end result merely that athletes and nonathletes ultimately work in different industries but for comparable pay? An answer to this 
question will clarify whether concern over clustering has a valid economic component. With this information in hand, universities can develop more informed policies and alleviate problems that stem from athlete clustering.

\section{Why Do Athletes Cluster?}

Clustering occurs when athletes join up with other athletes (often their own teammates) in a narrow selection of academic majors. The practice appears to be widespread. An investigation printed in the USA Today, for example, examined 142 schools and found that clustering occurred at $83 \%$ of them (Upton \& Novak, 2008). While the specific majors chosen by athletes tend to vary across teams (Leiber Steeg, et al., 2008), majors within the social sciences are most often selected (Fountain \& Findlay, 2009). Exactly why athletes are more likely than other students to major in the social sciences is less clear. There are two predominant theoretical explanations: a selection hypothesis and structure hypothesis.

\section{The Selection Hypothesis}

The selection hypothesis holds that participation in college athletics is selective of a unique population of students. According to this view, student-athletes begin college more disposed than nonathletes toward a unique set of academic majors-namely, those majors that are perceived to best facilitate successful participation in college athletics. There is some indirect evidence in support of this claim. First, compared with other high school students who possess college aspirations, high school athletes who aspire to play intercollegiate do less to academically prepare for college (Knight Foundation, 2001). Lesser college preparation on the part of athletes may make them less inclined than nonathletes to consider academia's more challenging majors.

Second, athletes tend to have lower high school grade point averages (GPAs) and standardized test scores than nonathletes who are admitted to the same schools (Bowen \& Levin, 2003). For example, Knobler (2008) conducted a nation-wide study and found that athletes who played either football or men's basketball had SAT scores that were an average of 220 points lower than their nonathlete classmates. Many universities, particularly those that operate high-profile athletic departments, have "lowered the bar" set for admissions to enroll lesser-qualified high-profile athletes who can foster public interest in school sport teams (Sperber, 2001). As of this writing, schools in every major athletic conference operate NCAA condoned special-admissions programs that improve athletes' odds of acceptance (Scher Zagier, 2009). According to Scher Zagier's research, odds of admission are as much as ten times higher for athletes. One outcome of this practice is that the average college athlete is less academically prepared for school than the nonathlete who enters the same school (Shulman \& Bowen, 2001). This may result in athletes possessing less interest in their school's more challenging academic majors than their nonathlete counterparts.

In sum, research has found that compared with nonathletes, student-athletes have unique academic interests and priorities upon entrance into college. Thus, incongruence in academic major decisions between college athletes and nonathletes may be driven by preexistent differences. To test this possibility, we examine whether college athletes make different choices than nonathletes when choosing 
their first academic majors Stated formally, our first hypothesis, which is the selection hypothesis, is that when choosing between social sciences and other potential academic majors, athletes will be more likely than nonathletes to select social sciences as a first major.

It is important to note, however, that studying athletes' first majors is not a perfect evaluation of the selection hypothesis. This is because most athletes have already been in close contact with coaches, teammates and other school representatives for months before matriculation. This precollege contact may lead new college athletes to alter initial decisions about academic majors. Influence of this type on academic major decisions would be consistent with an alternative hypothesis that emphasizes the effects of structural forces on college athletes.

\section{The Structure Hypothesis}

The structure hypothesis argues that clustering stems from the experience of college athletics itself. According to this view, participation in college athletics places athletes into environments that pressure them to choose academic majors that are most compatible with fulfillment of the student-athlete role. Thus, according to this second view, external influences are most accountable for athlete clustering. There is some indirect evidence in support of this claim.

First, commitments that come with participation in college athletics leave limited room for academics in athletes' lives. It is common for student-athletes to devote over 25 hours per week to their sport while in season (Bowen \& Levin, 2003; Shulman \& Bowen, 2001). Moreover, athletes tend to make additional "mental time commitments" to sport by thinking and talking about it even when not practicing or performing (Alder \& Alder, 1991). Student-athletes also miss a significant amount of class time due to travel. Many must cope with fatigue and injuries that come with athletic participation. These multiple demands and stresses that are associated with college athletics are thought to multiplicatively hinder athletes' commitment to academics (Cantor \& Prentice, 1996; Simons, Van Rheenen, \& Covington, 1999).

Second, the cultural norms of college athletics are believed to discourage student-athletes from mingling with other students and also dissuade athletes from emphasizing academics over sports (Alder \& Alder, 1991; Sperber, 2001). As argued by Pascarella and colleagues (1999), "the norms of the athletic subculture...isolate [athletes] from the kinds of interaction with diverse student peers and faculty that enrich the intellectual experience of college." Instead, college athletes' interactions both in and out of school tend to be mostly with other athletes, particularly with teammates (Bowen \& Levin, 2003). As a consequence, athletes feel exaggerated social pressure to conform to team expectations (Yusko, Buckman, White, $\&$ Pandina, 2008). The heightened social pressure experienced by athletes may prevent them from making their own decisions about college majors. In contrast, nonathletes' peer groups appear to have little to no influence on their academic major choices (Goza \& Ryabov, 2009).

In sum, the structure hypothesis states that athlete clustering results mostly from heavy demands placed on athletes and the cultural norms of college athletics. As a test of the structure hypothesis, we examine whether college athletes make different choices than nonathletes when selecting a final academic major net of first academic major. If structure plays no part in athlete clustering, athletes should 
not be more likely than others to choose social sciences as their final major once differences in initial academic major preferences are accounted for. Thus, our second hypothesis, the structure hypothesis, is that when choosing between social sciences and other potential academic majors, athletes will be more likely than nonathletes to select social sciences as their final major, even when controlling for first academic major.

To summarize, a research finding that athletes make different choices than nonathletes at time of first academic major would support the selection hypothesis. In contrast, the structure hypothesis would receive support from a research finding that differences in academic major preferences between athletes and nonathletes are more pronounced at time of final academic major than at time of first academic major. As a note, the selection hypothesis and the structure hypothesis are not mutually exclusive. It is possible that athletes and nonathletes enter school with different academic majors in mind, but that differences are exacerbated by unique structural forces that push student-athletes into an increasingly narrow set of academic majors. Analyses presented here will evidence whether this caveat has merit.

\section{Which Athletes Cluster Most Often?}

Demographic and social factors can greatly influence the academic experiences of college athletes (e.g., Harrison, et al., 2009; Hoberman, 2000; Yusko, et al., 2008). This paper examines whether two demographic traits, gender and race, as well as participation in revenue generating sports, or "high-profile" sports, moderate the relationship between athletic participation and college major. Past research has suggested these factors may play significant roles in athlete clustering.

\section{Gender}

On the whole, female athletes have more academic success than their male athlete counterparts. Female athletes have been found to take education more seriously (Simons, et al., 1999), receive better grades (Settles, Sellers, \& Damas, 2002) and graduate at a significantly higher rates (Hildenbrand, Sanders, Leslie-Toogood, \& Benton, 2009), even when important background factors (e.g., SAT scores) are taken into consideration (Bowen \& Levin, 2003). Women's greater academic achievements are thought to stem in part from a lack of professional opportunities for female athletes, which leads them to place more emphasis on schoolwork (Harrison \& Lawrence, 2004). To the degree that commitment to schoolwork guards against clustering, one would expect female athletes to cluster less often than male athletes. Based on this expectation, our third hypothesis, which we call the gender hypothesis, is that when choosing between social sciences and other potential academic majors, male athletes will be more likely than female athletes to choose the social sciences.

\section{Race}

Race may also shape the decision to cluster (or not to cluster) with other athletes. Compared with White athletes, African American athletes are more likely to be recruited solely for their ability to generate revenue and fame for an institution 
through sport (Woods, 2007). A consequence is that African American athletes are more likely than other students to be academically ill-prepared for college and little effort is made to remedy the gap, as evidenced by their lower graduation rates (Splitt, 2007). These factors may push a disproportionate number of African American athletes away from academic majors that require a stronger academic background.

Second, African American athletes are more likely than athletes of other races to believe they can earn a living playing professional sports (Sellers \& Kuperminc, 1997). Consequently, young African American athletes tend to overestimate their chances of playing professional sport, which leads them to shortchange their academic development (Hoberman, 2000). Many African American college athletes, for example, admitted they would only do the minimum required to stay eligible in school and would leave before graduating if an opportunity to play professional sports presented itself (Hutchinson, 2004). African American athletes' greater focus on sports may preclude them from selecting into some of academia's more challenging majors, leading them to instead prefer academic majors that seem to better facilitate the development of an athletic career.

Finally, African American athletes report feeling isolated on college campuses (Center for the Study of Athletics, 1989). Some of this isolation stems from the tendency of others to stereotype them as academically inferior students (Sailes, 1996). Because African American athletes feel isolated, they tend to create peer networks comprised mostly of other African American athletes (Melendez, 2008). Research examining the role of peer networks on academic major choices found that African American students whose peer network is mostly African American are at risk for ostracism when they choose an academic major that is not commonly held within the peer network (Goza \& Ryabov, 2009). Thus, African American athletes may band together within a smaller number of academic majors to conform to peer expectations (Harrison Jr, Harrison, \& Moore, 2002). Consequently, our fourth hypothesis, the race hypothesis, is that when choosing between social sciences and other potential academic majors, African American athletes will be more likely than athletes of other races to choose the social sciences.

As a note, there is some evidence that socioeconomic status (SES) influences college major choice (Leppel, Williams, \& Waldauer, 2001). SES, then, may also moderate the relationship between athletic participation and clustering. Data analyzed here do not include SES measures and this is a limitation of the current study. Future research should examine the role of SES in college athletes' academic majors.

\section{High-Profile Sports}

Athletes who play the revenue generating sports of college football, men's basketball, or women's basketball may be especially likely to cluster. Studies have evidenced that these athletes, on the whole, are less concerned about their education than other athletes (Simons, et al., 1999). They are also most likely to experience "role engulfment", a condition in which athletes becomes fixated solely on their athletic responsibilities (Alder \& Alder, 1991). Football and basketball are the college sports in which participants are most likely to dream of a professional career (Woods, 2007). The heightened emphasis on professional opportunities within high-profile sports may lead participants to choose majors that are thought to conflict less with extreme commitment to athletic development. Thus, our fifth 
hypothesis, the high-profile sport hypothesis, is that when choosing between social sciences and other potential academic majors, high-profile athletes will be more likely than other athletes to choose the social sciences.

\section{Does Clustering Produce Income Inequality?}

There is concern that athlete clustering fosters future income inequalities between athletes and nonathletes (Leiber Steeg, et al., 2008). Compared with vocational fields (e.g., engineering, health, and business), the pathway from graduation to employment in the social sciences appears to be less direct (Spalter-Roth, Van Vooren, \& Senter, 2009). Moreover, pay tends to be lower in industries that contain a high proportion of college graduates with social science degrees (Roksa, 2005). Athletes' greater presence in the social and behavioral sciences, then, may lead to future income inequalities; although there is some evidence that former college athletes earn slightly more than others who work in the same industries (Henderson, Olbrecht, \& Polachek, 2006). Our sixth hypothesis, the diminished income hypothesis, is that due to athletes'greater presence in the social sciences, athletes will have lower projected incomes than nonathletes.

Other research suggests that clustering within social science majors may not economically disadvantage college athletes. Although clustering limits the presence of athletes in academia's most financially rewarding majors, clustering also keeps athletes out of academic majors that feed low earning occupational fields, such as arts and humanities (Roksa, 2005). Moreover, Torpey (2008) found that workers who majored in the social sciences saw the greatest income increases over a tenyear period. Although their incomes were initially lower, workers who majored in the social sciences had higher annual incomes, on average, ten years past graduation than those who majored in education, mathematics, and even the biological sciences. This suggests that groups who major in the social sciences may initially have comparatively low incomes, but that the gap is erased and reversed over time. Thus, athletes' propensity to cluster within the social sciences may mean that their projected earnings fair comparably to those of nonathletes-particularly in the longterm. Accordingly, our seventh hypothesis, the rebounding income hypothesis, is that athletes will have higher projected incomes than nonathletes when projected incomes are based on expected earnings ten years past graduation.

\section{Data and Method}

Data are from a student database provided by a Midwestern land grant university. The database includes records for all 13,970 undergraduate students who enrolled in the mid-1990s. There are five distinct cohorts in the dataset: 1993 enrollees, 1994 enrollees, 1995 enrollees, 1996 enrollees, and 1997 enrollees. Rather than examine cohorts individually, we collapse them together to create a sample with a larger number of student-athletes $(n=385)$, hence increasing statistical power. Students who enrolled for only one semester $(n=1,218)$ and/or students who never declared a major $(n=350)$ are excluded from analyses, thus leaving 12,402 students in analyses. The dataset contains as much seven years, or 14 semesters (spring and summer semesters combined), of information for each student. 


\section{Variables}

First Major and Final Major Are the Dependent Variables. They are categorical and are grouped into ten categories similar to those found in the Baccalaureate and Beyond Longitudinal Study conducted by the U.S. Department of Education (Torpey, 2008): arts and humanities, biological sciences, business management, computer science, education, engineering, health, math and physics, other careers, and social sciences.

The main independent variable is athlete. It is a binary measure. Any student marked as an athlete for two or more semesters in the seven-year period receives a value of one. The rest are given a zero. To test whether clustering is more common among subgroups of athletes (see Background), three interaction variables are created: male athlete, African American athlete, and high-profile athlete. Athletes are designated as high-profile athletes if they played football, men's basketball or women's basketball.

The statistical models control for ACT scores and high school GPA because these partially predict college major (Arcidiacono, 2004). A small proportion of students (13.39\%) lack either an ACT score and/or a high school GPA. As scores appear to be missing at random, multiple imputation fills in missing values (Acock, 2005). ACT and high school GPA scores are imputed from sex, race, geographic region, college athletic status, cohort, semesters completed, semester and cumulative GPAs, ACT score (when available), and high school GPA (when available). Additional analyses (available upon request) indicate that excluding students with missing data does not meaningfully change model coefficients or significance test results. Thus, the results presented here are not skewed by imputation assumptions. Sex and race are also included as control measures as they too predict college major (Dickenson, 2010). Whites serve as the reference racial category.

\section{Procedures}

Multinomial Logistic Regressions. Because first and final academic major, the dependent variables, have multiple categories, multinomial logistic regression is used to test their association with athletic status. Multinomial logistic regression is preferred for models containing categorical dependent variables because such variables violate linear regression assumptions of homoscedasticicity and normality of distribution (Hoffmann, 2004). As athletes cluster most often within the social sciences, social sciences serves as the base category in the models presented here. The models, then, determine whether athletes are less likely than nonathletes to select a major outside of the social sciences. Models presented here can be expressed as $y i=\pi(\mathrm{x} i)+\varepsilon i$, where $y i$ represents the odds of choosing a major outside of the social sciences, $\pi(\mathrm{x} i)$ represents the conditional probability of making this choice given the independent predictor variables, and $\varepsilon i$ represents the random error term.

Although we have population-level data for a single university, we run statistical significance tests. These are included for heuristic purposes as we cannot strongly claim the results presented here are inferential to other universities. We do note, however, that our results are consistent with research on athlete clustering that has examined multiple schools (e.g., Fountain \& Findlay, 2009; Upton \& Novak, 
2008). Regardless, it may be best to consider our findings as preliminary and/or exploratory due to the unavailability a national sample of students.

Finally, to keep the manuscript's length in check, Table 1 and Table 2, which present the results of our multinomial logistic regression models, only show odds ratios and results from significance tests. We present odds ratios here rather than coefficients because they are more easily interpreted when dependent variables are categorical. An odds ratio of 10.0, for example, would mean that the odds that one group (e.g., athletes) experiences a condition (e.g., majoring in the social sciences) are 10 times greater than the odds that another group (e.g., nonathletes) experience the same condition. Conversely, an odds ratio of 0.1 would mean that the odds of one group experiencing a condition are 1/10th the odds that another group experiences the same condition.

Academic Major Graphs. To further illustrate increases in athlete clustering over time, a measure of major heterogeneity across eight semesters is graphed for each of the following groups: nonathletes, all athletes, male athletes, African American athletes, and high-profile athletes. Heterogeneity scores are calculated by (1) adding the sums of each major's squared probability together, then (2) subtracting the total from one, or $1-\Sigma p_{i}^{2}$. A score of zero represents perfect congruence (all people in a group share the same major) and increasing scores represent increasing heterogeneity in majors. A second graph containing the proportion of the respective groups majoring in the social sciences at each semester is also presented.

Income Projection Graphs. To illustrate how increased athlete clustering across semesters impacts future income projections, graphs containing short-term income projections (i.e., one year post graduation) and long-term income projections (i.e., ten years post graduation) are presented. Income projections are derived from data in the Baccalaureate and Beyond Longitudinal Study conducted by the U.S. Department of Education, which reported on the average earnings of bachelor's degree recipients who are working full time (Torpey, 2008).

\section{Results}

\section{Descriptive Summary}

Table 3 contains the sample means and standard deviations of the variables included in the analyses. Engineering is most frequently selected as a first major (19.8\%), followed by other careers $(18.5 \%)$ business management $(16.0 \%)$, education $(11.1 \%)$, biological sciences $(9.7 \%)$, social sciences $(7.0 \%)$, arts and humanities $(5.0 \%)$, computer science $(3.3 . \%)$, and math and physics $(1.1 \%)$. With respect to final major, engineering remains the most popular $(17.0 \%)$, followed by other careers $(15.2 \%)$, business management $(17.0 \%)$, social sciences $(12.2 \%)$, biological sciences $(10.6 \%)$, education $(7.1 \%)$, arts and humanities $(5.0 \%)$, computer science (2.6\%), and math and physics $(1.1 \%)$.

Student-athletes comprise $3 \%$ of the sample. Male athletes make up $2 \%$ of the sample, African American athletes are $.05 \%$ of the sample and high-profile athletes are $1.3 \%$ of the sample. There are slightly more males $(50.5 \%$ of the sample) than females. Non-Hispanic Whites are by far the most common racial or ethnic group (92.0\% of the sample), followed by African Americans (3.1\%), Hispanics (2.2\%), Asians (1.8\%), Native Americans (0.7\%) and other racial groups $(0.2 \%)$. 


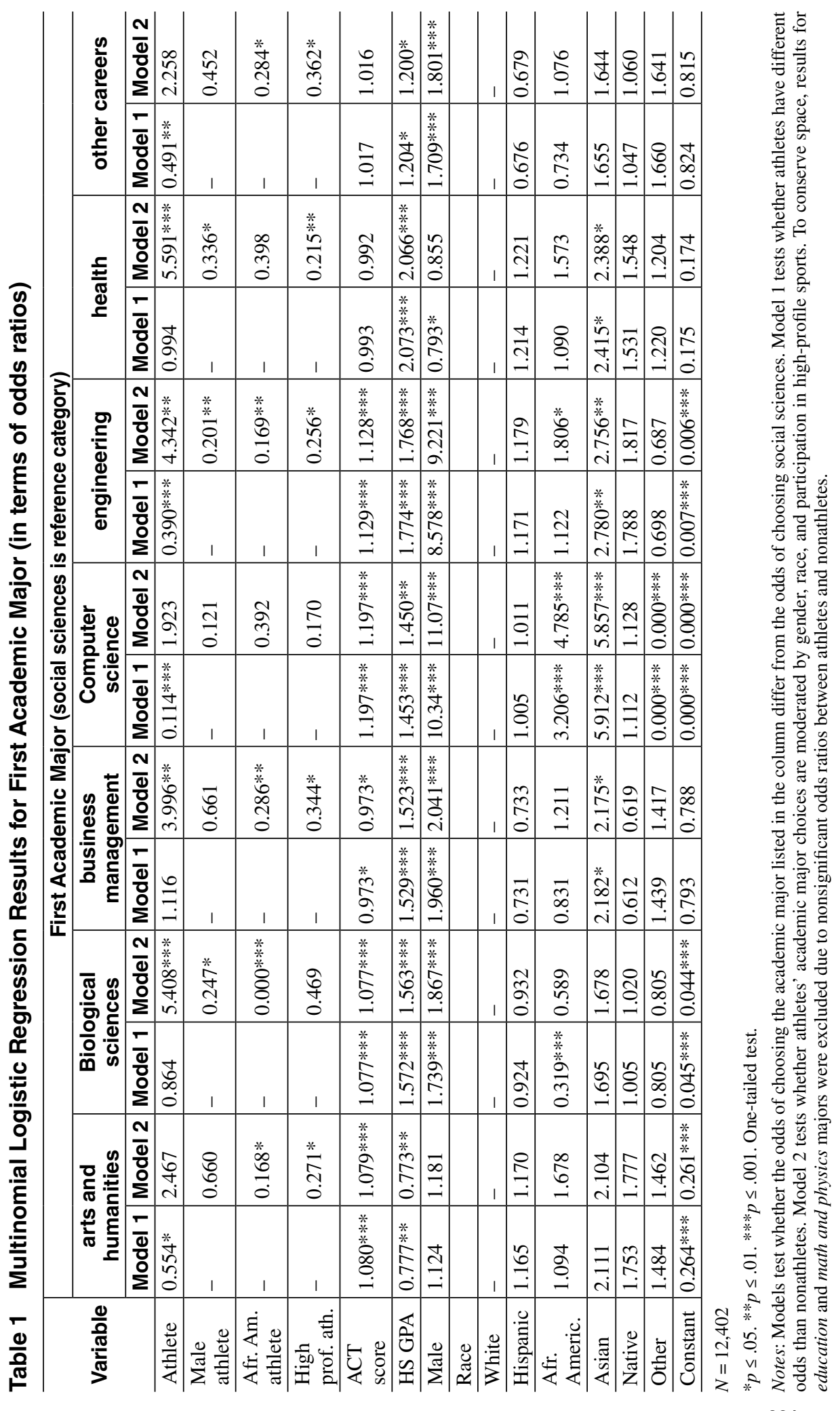




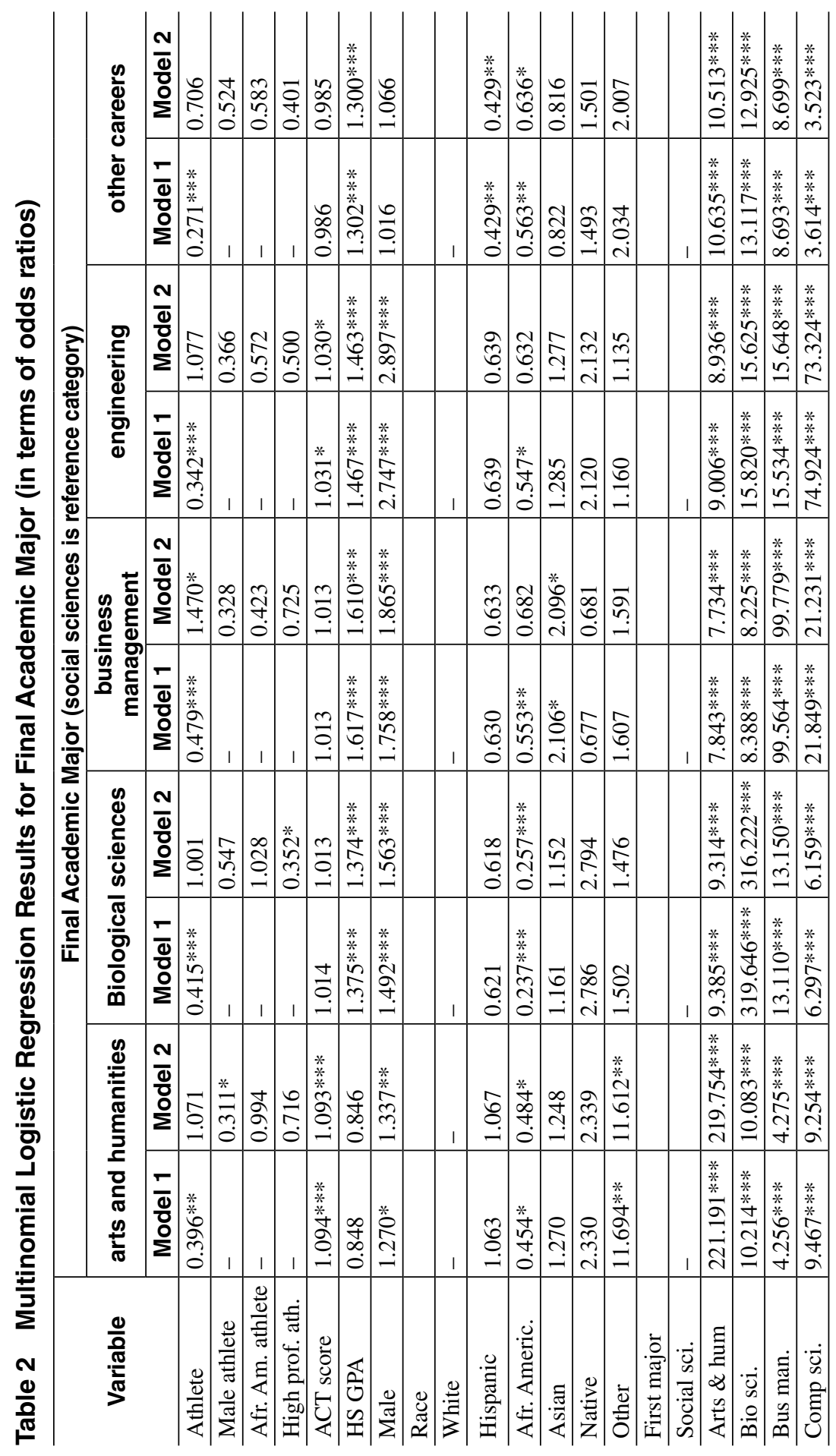




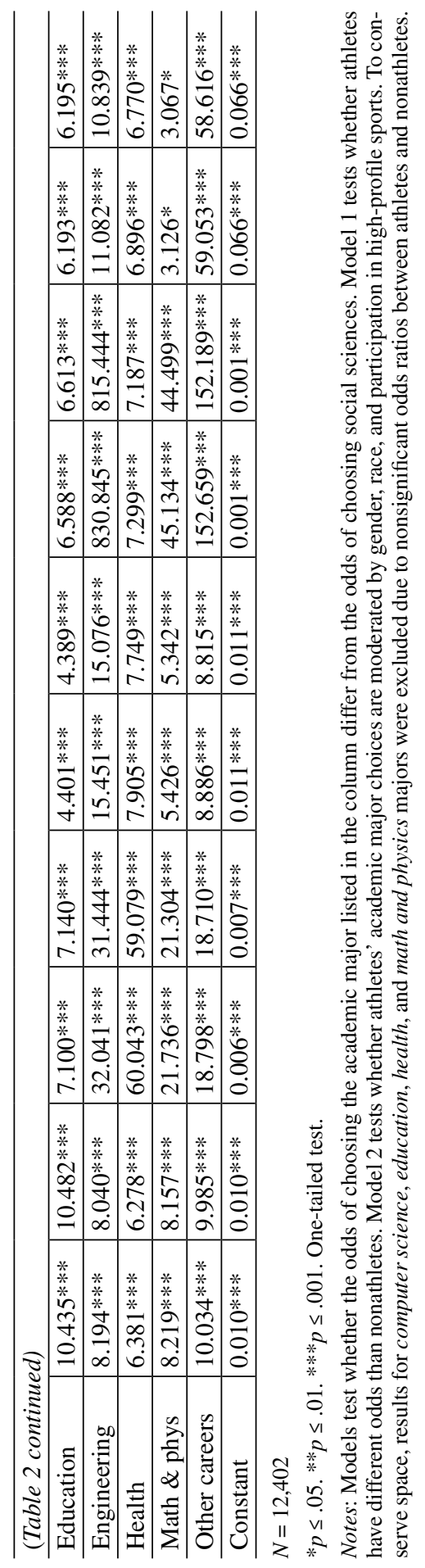


Table 3 Sample Means and Standard Deviations (SD)

\begin{tabular}{l|c|c|c}
\hline \multicolumn{1}{|c|}{ Variable } & Type & Mean & SD \\
\hline Dependent Variables & & & \\
\hline First major & Categorical & & \\
\hline Arts and humanities & & 0.050 & - \\
\hline Biological sciences & & 0.097 & - \\
\hline Business management & & 0.160 & - \\
\hline Computer science & & 0.033 & - \\
\hline Education & & 0.086 & - \\
\hline Engineering & & 0.198 & - \\
\hline Health & & 0.111 & - \\
\hline Math and physics & & 0.011 & - \\
\hline Other careers & & 0.185 & - \\
\hline Social sciences & Categorical & 0.070 & - \\
\hline Final major & & 0.050 & - \\
\hline Arts and humanities & & 0.106 & - \\
\hline Biological sciences & & 0.170 & - \\
\hline Business management & & 0.026 & - \\
\hline Computer science & & 0.103 & - \\
\hline Education & & 0.170 & - \\
\hline Engineering & & 0.071 & - \\
\hline Health & & 0.011 & - \\
\hline Math and physics & & 0.152 & - \\
\hline Other careers & Binary & 0.505 & - \\
\hline Social sciences & & 0.122 & - \\
\hline Independent Variables & & & \\
\hline Athlete & Binary & 0.030 & - \\
\hline Male athlete & Binary & 0.020 & - \\
\hline African American athlete & Binary & 0.005 & - \\
\hline High profile athlete & Binary & 0.013 & - \\
\hline Controls & & & \\
\hline ACT score & & 0.920 & - \\
\hline High school GPA & & 0.022 & - \\
\hline Male & & 0.031 & - \\
\hline Race & & 0.018 & - \\
\hline White & & 0.007 & - \\
\hline Hispanic & & & - \\
\hline African American & & & \\
\hline Asian & & & \\
\hline Native & & & \\
\hline Other & & & \\
\hline & & & \\
\hline & & & \\
\hline 2,0792 & & & \\
\hline
\end{tabular}

$N=12,402$

Note: Means for first major, last major, and race categories add up to 1 (i.e., $100 \%$ of the sample). 


\section{Multinomial Logistic Regressions}

Comparisons of athletes' and nonathletes' first academic majors, presented in Model 1 of Table 1, suggest that athletes are prone to clustering at the start of their college careers. This finding provides support for the selection hypothesis. When given the option of initially declaring in social sciences or an alternative major, athletes have significantly lower odds than nonathletes of choosing arts and humanities $(0.55$ times the odds of nonathletes; $p \leq .05)$, computer science $(0.11$ times the odds of nonathletes; $p \leq .001)$, engineering ( 0.39 times the odds of nonathletes; $p \leq .001)$, and other careers ( 0.49 times the odds of nonathletes; $p \leq .001)$.

However, as shown in Model 2 of Table 1, athletes' likelihood of clustering within the social sciences at time of first major is heavily moderated by gender, race, and type of sport played. These findings lend support to our gender, race, and high-profile athlete hypotheses. In fact, given the option of initially majoring in social sciences or something else, athletes are more likely than nonathletes to pick biological sciences (5.41 times the odds of nonathletes; $p \leq .001$ ), business management (4.00 times the odds of nonathletes; $p \leq .001$ ), engineering (4.34 times the odds of nonathletes; $p \leq .01$ ), and health (5.60 times the odds of nonathletes; $p$ $\leq .001)$. That athletes' are more likely than nonathletes to pick these majors over social sciences, however, is obscured by the tendency of male athletes, African American athletes, and high-profile athletes to prefer social sciences over all other options. Thus, as predicted by the gender, race, and high-profile athlete hypotheses, male athletes, African American athletes, and high-profile athletes appear to be more at risk for clustering within the social sciences than others at the time of first major. In contrast, the risk of clustering at time of first major is minimal for female athletes, athletes who are not African American and athletes who do not play high-profile sports.

Comparisons of athletes' and nonathletes' final academic majors, presented in Model 1 of Table 2, suggest that athlete clustering intensifies over time, even when controlling for first academic major. This finding provides support for our structure hypothesis. When given the option of settling on social sciences or an alternative major, athletes are significantly less likely than nonathletes to pick arts and humanities ( 0.40 times the odds of nonathletes; $p \leq .01)$, biological sciences ( 0.41 times the odds of nonathletes; $p \leq .001)$, business management ( 0.48 times the odds of nonathletes; $p \leq .001)$, engineering ( 0.34 times the odds of nonathletes; $p \leq .001)$ and other careers (0.27 times the odds of nonathletes; $p \leq .001)$.

However, as shown in Model 2 of Table 2, athlete clustering at time of final major is again moderated by athletes' gender, race, and type of sport played. This finding lends additional support to our gender, race, and high-profile athlete hypotheses. In fact, given the option of eventually majoring in social sciences or business management, more athletes than nonathletes switch over to business management (1.47 times the odds of nonathletes when controlling for first academic major). That athletes' are more likely than nonathletes to move into business management, however, is obscured by the tendency for male athletes, African American athletes, and high-profile athletes to prefer social sciences over all other options. Thus, as predicted by the gender, race, and high-profile athlete hypotheses, male athletes, African American athletes, and high-profile athletes are at greater risk than others of clustering within the social sciences at the time of final major. In contrast, the 
risk of clustering at time of final major is again low for female athletes, athletes who are not African American and athletes who do not play high-profile sports.

\section{Academic Major Graphs}

To illustrate prevalence of athlete clustering at each semester, Figure 1a presents a measure of major heterogeneity for several groups of athletes and nonathletes across eight semesters. Although athletes, in general, have less heteronomy in major selection than nonathletes, African American athletes not only begin with much less heteronomy than other groups, but also cluster with increasing frequency as semesters progress. To a lesser extent, this trend is also characteristic of high-profile athletes in general.

Figure $1 \mathrm{~b}$, which presents the proportion of each group majoring in social science, further illustrates the increases in African American athlete clustering across semesters. At first semester, the difference in proportions between all groups is negligible. Over time, athletes (and nonathletes) become increasingly likely to major in social sciences. African American athletes, however, are far more likely than all other groups to eventually choose to major in the social sciences. By eighth semester, $64 \%$ of African American athletes are social science majors, which is more than seven times the number who initially chose to major in the social sciences.

\section{Income Projection Graphs}

Figure $2 \mathrm{a}$ presents projected short-term (i.e., one year after graduation) incomes for groups based on academic majors. Athlete clustering resulted in depressed income projections in the short term. This finding provides support for our diminished income hypothesis. The effect of clustering on lowered short-term incomes is most pronounced among African American athletes. African American athletes as a whole initially select majors that project them to have the highest short-term incomes, $\$ 33,682$ or $\$ 832$ more than nonathletes. However, clustering drives the projected short-term income down to $\$ 28,950$ by the eighth semester of college, which is $\$ 2,882$ less than nonathletes.

Figure $2 \mathrm{~b}$ presents the projected long-term (i.e., ten years after graduation) incomes values for each group. This illustration suggests that certain groups' longterm incomes may actually benefit from their propensity to cluster within the social sciences (although it would take years for an income advantage to emerge). Although nonathletes' again project to have higher incomes (\$290 more) than athletes in general, the subgroups of athletes who cluster most frequently (i.e., male athletes, African American athletes, and high-profile athletes) end up with higher projected long-term incomes than nonathletes (between \$132 and \$570 more).

\section{Discussion}

Athlete clustering has received significant media attention, but only a few studies have examined the issue. We have extended the research by seeking answers to three critical questions about clustering. First, why do athletes cluster? Second, which athletes cluster most? And third, does clustering engender income inequalities post graduation? 


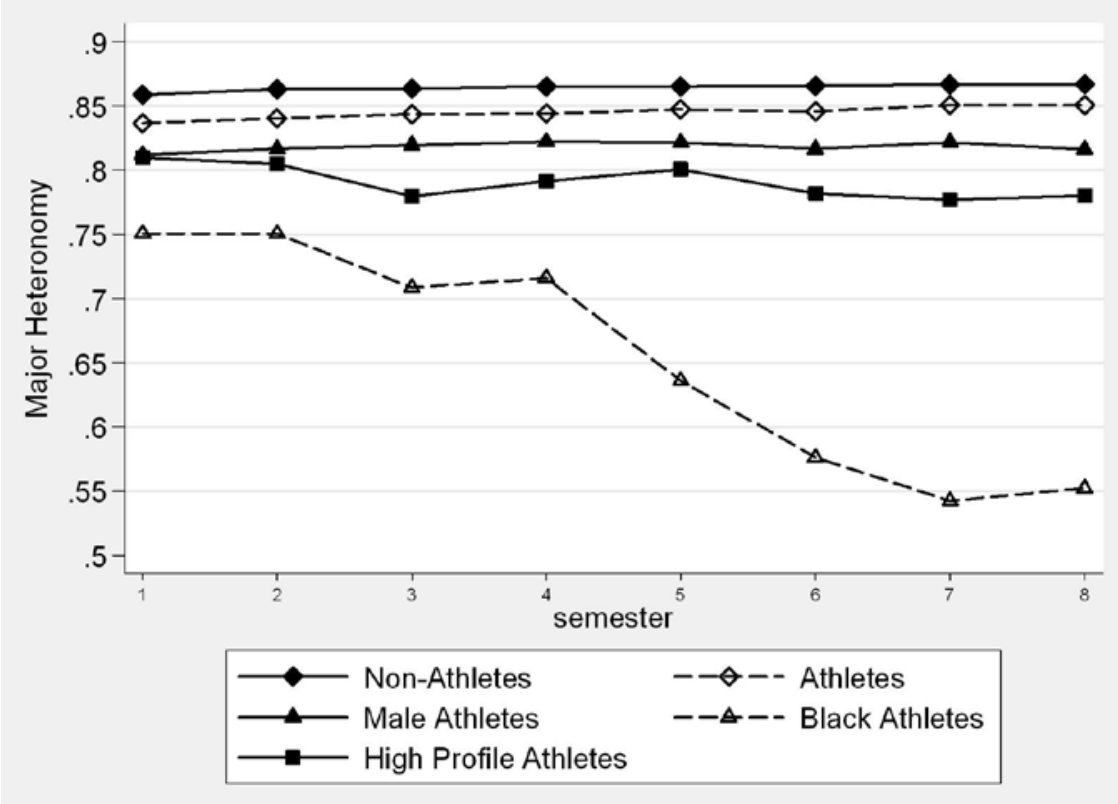

a

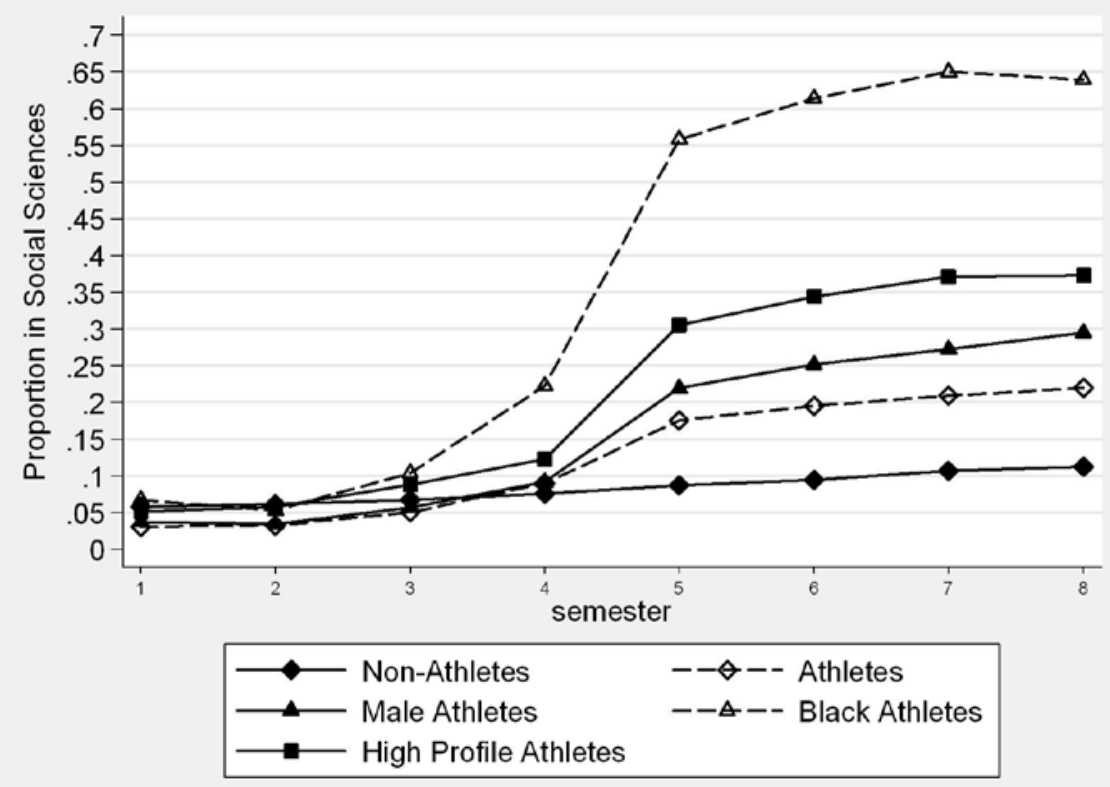

b

Figure 1 - a. Major Heteronomy by Semester. b. Proportion of Social Science Majors by Semester 


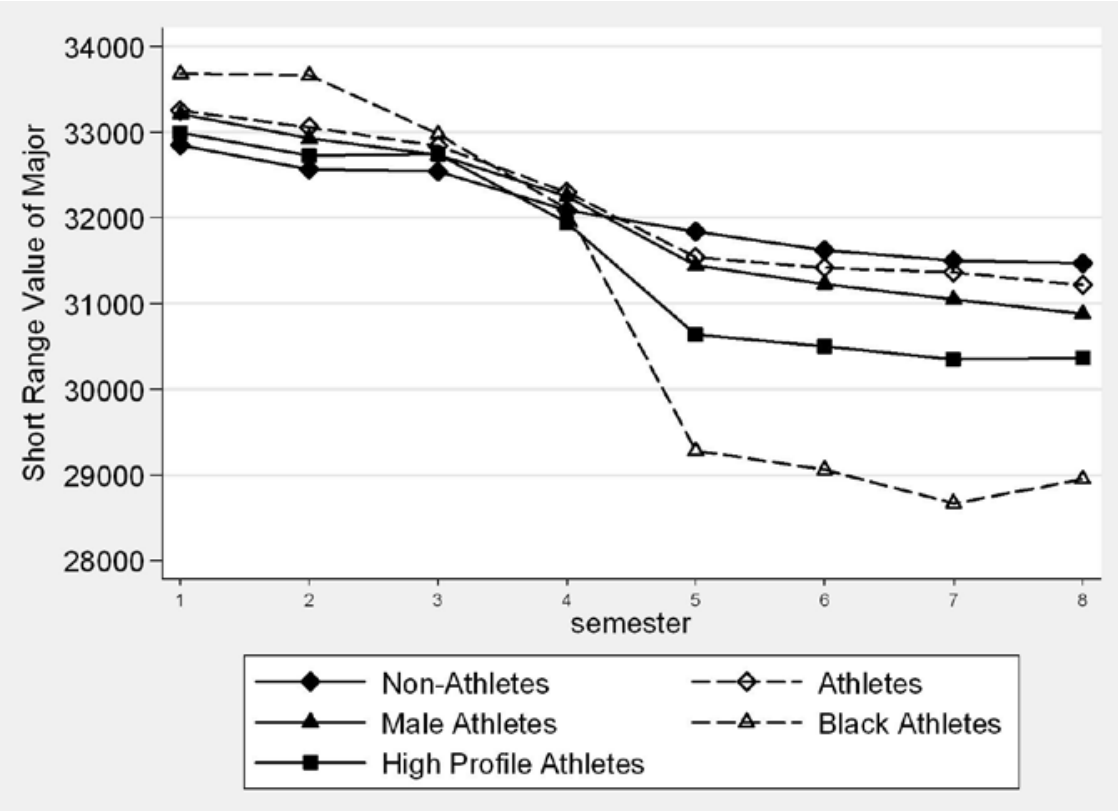

a

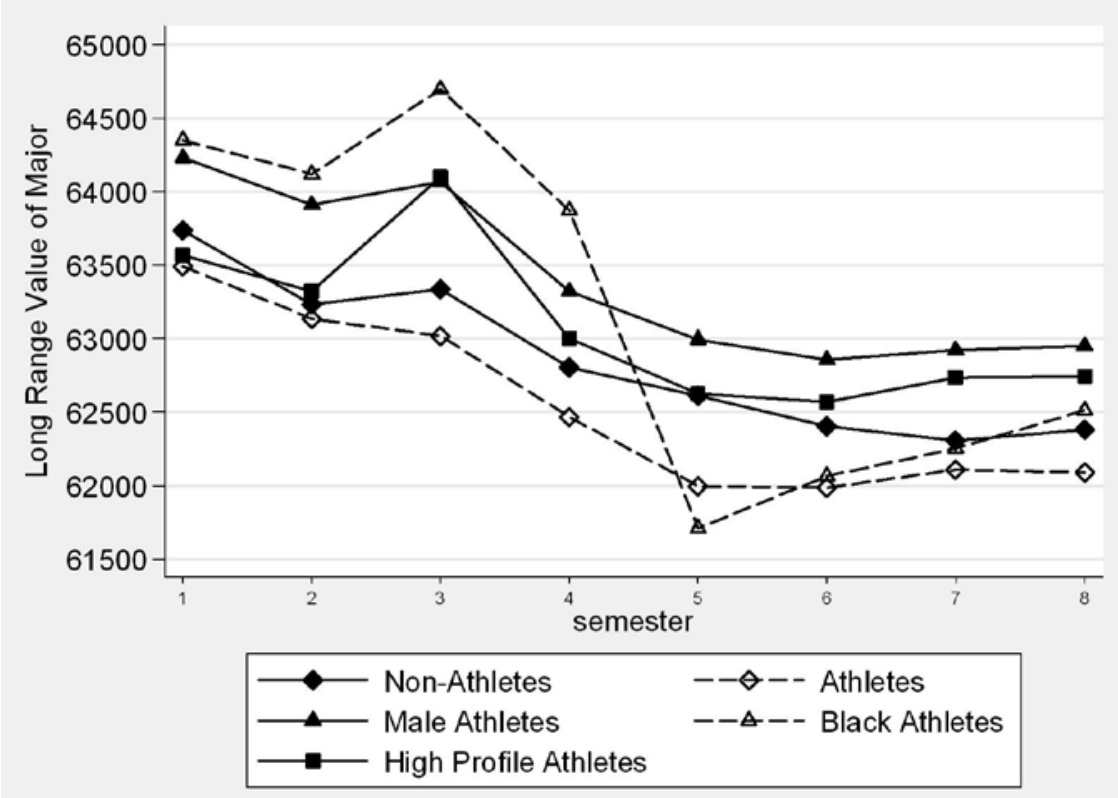

b

Figure 2 - a. Projected Short-Term Income (Based on Academic Major) by Semester. $\mathrm{b}$. Projected Long-Term Income (Based on Academic Major) by Semester 


\section{Why Do Athletes Cluster?}

The first issue examined was whether athlete clustering occurred upon college entrance (as predicted by a selection hypothesis) or later on (as predicted by a structure hypothesis). Results suggested that the answer is "both". Athletes are initially more likely than nonathletes to choose social sciences over arts and humanities, computer science, engineering, and other careers. This is consistent with findings that high school athletes who aspire to play in college possess unique academic interests and priorities (e.g., Cantor \& Prentice, 1996). We also found, however, that some athlete clustering patterns do not emerge until later on their college careers. For example, athletes end up only half as likely as nonathletes to prefer the biological sciences and business management over the social sciences, but the odds are initially comparable. These findings are consistent with research that suggests participation in college athletics compels students to adjust academic goals and priorities to manage the demands of college athletics (e.g., Alder \& Alder, 1991; Shulman \& Bowen, 2001).

\section{Which Athletes Cluster?}

The simple statement that athletes cluster upon matriculating and continue this pattern with increasing intensity, however, masks wide discrepancies in college athletes' experiences. We found that athlete clustering was greatly moderated by demographic and social factors. By a wide margin, athlete clustering is most prevalent among African Americans (and at all stages of their college careers). To a lesser extent, athletes who play big-time sports and male athletes are also affected (see Upton \& Novak, 2008 for similar findings). In contrast, clustering appears to be a relative nonissue for athletes who are female (Harrison, et al., 2009), not African American (Woods, 2007) and not playing high-profile sports (Simons, et al., 1999).

Based on our results, then, athletes at greatest risk of clustering (by a very wide margin no less) are African American males who play high-profile sports (Hoberman, 2000). There are multiple reasons why. First, clustering likely stems in part from universities' greater willingness to recruit high profile African American athletes for purposes of revenue and fame (Woods, 2007). One result of this type of recruitment is that a disproportionate share of these athletes is ill-prepared for college-level academics. And once admitted, these students are offered insufficient institutional support when it comes to getting up to speed academically (Splitt, 2007).

Second, clustering may also be so magnified by high-profile African American male athletes' willingness to focus on athletics at the expense of academics (Hawkins, 2010). Although the degree to which it occurs tends to be overstated, these athletes are the most likely group to believe a future career in sport awaits them (Smith, 2009). This expectation - to the degree that it is held-renders athletes more willing to overlook academic development (Hutchinson, 2004). Consequently, many prefer to "major in eligibility" rather than find an academic field that genuinely interests them (Upton \& Novak, 2008).

Finally, clustering is likely furthered by the limited amount contact between high-profile African American male athletes' and other students (Sailes, 1996). While at school, these athletes tend to establish highly homogenous peer networks comprised of many of their teammates and other athletes (Melendez, 2008). This 
type of peer network structure influences athletes to conform to group expectations more often than others, even when they would rather not (Yusko, et al., 2008). As academic commitment is viewed with ambivalence or worse in their peer networks (Harrison Jr, et al., 2002), high-profile African American male athletes risk a greater penalty for pursuing their own academic interests. For example, none of the African American athletes $(n=65)$ in our dataset declared either biological sciences or math and physics as an academic major. Although it is possible, it seems unlikely that both of these subjects failed to interest a single one of them.

\section{Does Clustering Promote Income Inequalities?}

Clustering has been criticized because it precludes athletes from academia's most financially rewarding majors (Steeg, 2008). As predicted by our diminished income hypothesis, we found that athletes' projected incomes (based on academic major) were lower than nonathletes' projected incomes one year out of college due to clustering. African American athletes were most impacted here as well. Their academic major preferences upon college entrance cause them to have the highest initial income projections, but the gap disappears by fourth semester, reverses at fifth semester, and their projected incomes are more than $\$ 1,000$ lower than the next lowest group by eighth semester. The findings based on short-term income projections, then, suggest that clustering can contribute to future income inequalities. Moreover, early wage gaps between athletes and nonathletes may be compounded by initial difficulties that social science majors have in finding work after graduation (Spalter-Roth, et al., 2009).

Projections based on long-term incomes, however, suggest that income inequalities engendered by clustering may be temporary. Ten years post graduation, groups of athletes that cluster most are projected to have higher incomes than nonathletes. This is because workers with social science degrees see the greatest increases in income between 1 and 10 years after graduation (Torpey, 2008). One limitation of this study is that we were only able to project future incomes rather report actual incomes. When employers hire former college athletes, it appears they pay an extra premium for their services (Henderson, Olbrecht, \& Polachek, 2006). Thus we may be overstating short-term deficits and even understating long-term excesses in pay for certain groups of athletes. In addition, our projects fail to take into account whether students graduate. Research suggests that athletes' graduation rates now surpass graduation rates of nonathletes (Hildenbrand, et al., 2009), but African American athletes and those who play high-profile sports still appear to have much lower graduation rates (Eckard, 2010; Woods, 2007). Variation in graduation rate across groups, which we have not accounted for here, would introduce additional error into our future income projections. Future research would do well to track a sample of college athletes and nonathletes beyond graduation to better establish the degree to which clustering may impact future earnings.

A final limitation of our study is that data examined were from only one school. Future research will hopefully analyze a longitudinal dataset comprised of studentathletes and nonathletes from many schools. In particular, it would be beneficial to look at the experiences of female African American athletes. In our dataset African American male athletes greatly outnumbered African American female athletes. Thus, our findings may be more representative of the formers' experiences. 
This study has provided new evidence that athlete clustering is common and can produce negative outcomes. Some clustering occurs at matriculation, but the magnitude increases greatly as semesters advance-particularly for African American athletes. As it stands, much more can be done to mitigate clustering to allow athletes more freedom of academic choice. Schools would do well to craft admissions policies that protect students from being unfairly used so that others can profit (Hawkins, 2010), develop institutional supports that emphasize academic growth rather than academic eligibility (Smith, 2009), limit athletic demands that can be placed on student-athletes (Bowen \& Levin, 2003), and promote meaningful classroom and campus interaction between athletes and nonathletes (Sailes, 1996). If implemented effectively, these types of policies and programs can help ensure that the decision to pursue one academic major rather than another is no longer compromised by participation in college athletics.

\section{References}

Acock, A. (2005). Working with missing values. Journal of Marriage and the Family, 67, 1012-1028.

Alder, P.A., \& Alder, P. (1991). Backboards \& blackboards: College athletes and role engulfment. New York: Columbia University Press.

Arcidiacono, P. (2004). Ability sorting and the returns to college major. Journal of Econometrics, 121(1-2), 343-375.

Bowen, W.G., \& Levin, S.A. (2003). Reclaiming the game: College sports and educational values. Princeton, NJ: Princeton University Press.

Cantor, N.E., \& Prentice, D.A. (1996). The life of the modern-day student athlete: Opportunities won and lost. Paper presented at the Princeton Conference on Higher Education.

(1989). Center for the Study of Athletics. Palo Alto, CA: Studies of Intercollegiate Athletes.

Dickenson, L. (2010). Race and Gender Differences in College Major Choice. The Annals of the American Academy of Political and Social Science, 627, 108-124.

Eckard, E.W. (2010). NCAA Athlete Graduation Rates: Less than Meets the Eye. Journal of Sport Management, 24(1), 45-59.

Foundation, K. (2001). A call to action: Reconnecting college sports and higher education. Miami, FL: John S. and James L. Knight Foundation.

Fountain, J.J., \& Findlay, P.S. (2009). Academic majors of upperclassmen football players in the Atlantic Coast Conference: An analysis of academic clustering comparing white and minority players. Journal of Issues in Intercollegiate Athletics, 2, 1-13.

Goza, F., \& Ryabov, I. (2009). Adolescents' Educational Outcomes: Racial and Ethnic Variations in Peer Network Importance. Journal of Youth and Adolescence, 38(9), 1264-1279.

Harrison, C.K., \& Lawrence, S.M. (2004). Female and male student athletes' perceptions of career transition in sport and higher education: A visual elicitation and qualitative assessment. Journal of Vocational Education and Training, 56(4), 485-506.

Harrison, C.K., Stone, J., Shapiro, J., Yee, S., Boyd, J.A., \& Rullan, V. (2009). The Role of Gender Identities and Stereotype Salience with the Academic Performance of Male and Female College Athletes. Journal of Sport and Social Issues, 33(1), 78-96.

Harrison, L., Jr., Harrison, C.K., \& Moore, L.N. (2002). African American racial identity and sport. Sport Education and Society, 7(2), 121-133.

Hawkins, B. (2010). The new plantation: Black athletes, college sports and predominantly White NCAA institutions. New York: Palgrave Macmillan.

Henderson, D.J., Olbrecht, A., \& Polachek, S.W. (2006). Do former college athletes earn more at work? A nonparametric assessment. The Journal of Human Resources, 41(3), $558-577$. 
Hildenbrand, K., Sanders, J.P., Leslie-Toogood, A., \& Benton, S. (2009). Athletic Status and Academic Performance at a NCAA Division 1 University. Journal for the Study of Sports and Athletes in Education, 3(1), 41-58.

Hoberman, J. (2000). The price of "Black dominance". Society, 37(3), 49-56.

Hoffmann, J.P. (2004). Generalized linear models: An applied approach. Boston: Pearson.

Hutchinson, E.O. (2004). Hornung was honest about black athletes, many universities aren't, from http://www.eurweb.com/story/eur13939.cfm.

Knobler, M. (2008, December 28). College athletes: academic performance: behind the line on grades. The Atlanta Journal-Constitution.

Leiber Steeg, J., Upton, J., Bohn, P., \& Berkowitz, S. (2008, November 18). College Athletes Studies Guided Toward 'Major in Eligibility'. USA Today.

Leppel, K., Williams, M., \& Waldauer, C. (2001). The impact of parental occupation and socioeconomic status on choice of college major. Journal of Family and Economic Issues, 22(4), 373-394.

Melendez, M.C. (2008). Black football players on a predominantly White college campus: Psychosocial and emotional realities of the Black college athlete experience. The Journal of Black Psychology, 34(4), 423-451.

Pascarella, E. T., Truckenmiller, R., Nora, A., Terenzini, P. T., Edison, M., \& Hagedorn, L. S. (1999). Cognitive impacts of intercollegiate athletic participation: Some further evidence. The Journal of Higher Education, 70, 1-26.

Roksa, J. (2005). Double disadvantage or blessing in disguise? Understanding the relationship between college major and employment sector. Sociology of Education, 78, 207-232.

Sack, A. (2009). Clashing models of commercial sport in higher education: Implications for reform and scholarly research. Journal of Issues in Intercollegiate Athletics, 2, 76-92.

Sailes, G.A. (1996). An investigation of campus stereotypes: The myth of Black athletic superiority and the dumb jock stereotype. In R.E. Lapchick (Ed.), Sport in society: Equal opportunity or business as usual? (pp. 193-202). Thousand Oaks, CA: Sage.

Scher Zagier, A. (2009). Admissions exemptions favor college athletes over other students Retrieved 5/24/10, from http://www.buffzone.com/ci_14099132

Sellers, R.M., \& Kuperminc, G.P. (1997). Goal discrepancy in African American male student-athletes' unrealistic expectations for careers in professional sports. The Journal of Black Psychology, 23(1), 6-23.

Settles, I., Sellers, R.M., \& Damas, A. (2002). One role or two? The function of psychological separation in role conflict. The Journal of Applied Psychology, 87, 574-582.

Shulman, J.L., \& Bowen, W.G. (2001). The game of life: College sports and educational values. Princeton, NJ: Princeton University Press.

Simons, H.D., Van Rheenen, D., \& Covington, M.V. (1999). Academic motivation and the student athlete. Journal of College Student Development, 40, 151-162.

Smith, E. (2009). Race, Sport and the American Dream. North Carolina: Carolina Academic Press.

Spalter-Roth, R., Van Vooren, N., \& Senter, M. S. (2009). Decreasing the Leak from the Sociology Pipeline: Social and Cultural Capital to Enhance the Post-Baccalaureate Sociology Career. American Sociological Association Department of Research and Development, 1-13.

Sperber, M.A. (2001). Beer and circus: How big-time college sports is crippling undergraduate education. New York: H. Holt.

Splitt, F.G. (2007). The Academic Performance of College Athletes: No Doubt Worse Than Reported. The Drake Group. Retrieved 4/15/10, from http://thedrakegroup.org/ Splitt_Academic_Performance_of_College_Athletes.pdf

Steeg, J.L., Upton, J., Bohn, P., \& Berkowitz, S. (2008). College athletes studies guided toward 'major in eligibility'. USA Today.

Torpey, E.M. (2008). The Class of 1993: Earning and Occupations by College Major 1 and 10 Years After Graduation. Occupational Outlook Quarterly, XXX, 15-25. 
Upton, J., \& Novak, K. (2008). College athletes cluster majors at most schools. USA Today. Woods, R.B. (2007). Social Issues in Sport. Champaign, IL: Human Kinetics.

Yusko, D.A., Buckman, J.F., White, H.R., \& Pandina, R.J. (2008). Risk for excessive alcohol use and drinking-related problems in college student athletes. Addictive Behaviors, $33(12), 1546-1556$. 